\title{
Effect of an Inhibitor of Lipid Peroxidation, U78517F, on C6 Astrocytoma Growth
}

\author{
Rolando F. Del Maestro, Christine R. Farrell, Eric Stroude and Warren McDonald
}

\begin{abstract}
A potent in vitro inhibitor of lipid peroxidation, U78517F, has been employed to assess its influence on C6 astrocytoma growth in monolayer culture and tumor growth and protein extravasation in the rat C6 astrocytoma spheroid implantation model. Results demonstrate that $1 \mu \mathrm{M}$ concentration of U78517F inhibits cell division, but is not tumoricidal to $\mathrm{C} 6$ astrocytoma cells in monolayer culture. Concentrations of $5 \mu \mathrm{M}$ and above significantly decreased astrocytoma cell viability. Following spheroid implantation, rats were treated with one of these U78517F regimes: 12 $\mathrm{mg} / \mathrm{kg} /$ day for 13 days post-implantation, $4 \mathrm{mg} / \mathrm{kg} /$ day for 13 days post-implantation or $12 \mathrm{mg} / \mathrm{kg} /$ day commencing seven days post-implantation until 13 days post-implantation. Tumor wet and dry weights were lower in all treatment groups, but these decreases were not statistically significant. Protein extravasation as measured by Evans blue extravasation was not significantly reduced by any treatment regime used. It is concluded that U78517F inhibits C6 astrocytoma growth in monolayer culture at and above $5 \mu \mathrm{M}$ concentrations, but the treatment regimes utilized did not significantly decrease tumor growth or permeability in the $\mathrm{C} 6$ astrocytoma spheroid implantation model.
\end{abstract}

RÉSUMÉ: Effet d'un inhibiteur de la peroxydation lipidique, le U78517F, sur la croissance de l'astrocytome C6 Nous avons utilisé un inhibiteur puissant de la peroxydation lipidique in vitro, le U78517F, pour évaluer son effet sur la croissance de l'astrocytome $\mathrm{C} 6$ en culture en couche monocellulaire ainsi que la croissance tumorale et l'extravasation protéique dans le modèle réalisé par implantation sphéroïde de l'astrocytome $\mathrm{C} 6$ chez le rat. Les résultats démontrent qu'une concentration de $1 \mu \mathrm{M}$ de U78517F inhibe la division cellulaire, mais n'est pas léthale pour les cellules d'astrocytome $\mathrm{C} 6$ en culture en couche monocellulaire. Des concentrations de $5 \mu \mathrm{M}$ et plus diminuaient de façon significative la viabilité des cellules d'astrocytome. Après implantation sphéroïde, les rats ont été traités au U78517F selon un des régimes suivants: $12 \mathrm{mg} / \mathrm{kg} /$ jour pendant 13 jours post-implant; $4 \mathrm{mg} / \mathrm{kg} / \mathrm{jours}$ pendant 13 jours post-implant; ou 12 $\mathrm{mg} / \mathrm{kg} / \mathrm{jours} \mathrm{du} 7^{\mathrm{e}}$ au $13^{\mathrm{e}}$ jour post-implant. Bien que le poids total et à l'état sec de la tumeur était plus faible dans tous les groupes traités, la diminution n'était cependant pas significative. L'extravasation des protéines telle que mesurée par l'extravasation du bleu Evans n'était significativement diminuée par aucun des modes de traitement utilisés. Nous concluons que le U78517F inhibe la croissance de l'astrocytome C6 en culture en couche monocellulaire à des concentrations de $5 \mu \mathrm{M}$ et plus, mais les plans de traitement utilisés n'ont pas diminué significativement la croissance ou la perméabilité de la tumeur dans le modèle réalisé par implantation sphéroïde de l'astrocytome C6.

Can. J. Neurol. Sci. 1991; 18: 7-11

The continued growth of brain tumors is associated with the development of tumor-associated edema which is an important determinant of patient morbidity and mortality. In both human brain tumors and animal brain tumor models, the mechanisms underlying the generation of tumor-associated edema remain undefined. 1.2 In glioblastoma multiforme, increased protein flux appears to be related to endothelial cell changes both in tumor microvessels ${ }^{3}$ and peritumoral tissue. ${ }^{4}$

The $\mathrm{C} 6$ astrocytoma spheroid implantation model is a glioma model in the rat which has many of the pathological and growth characteristics of human malignant gliomas. 5.7 Non-steroidal anti-inflammatory drugs (NSAIDS) and corticosteroids decrease protein extravasation as measured by a decrease in the flux of serum protein-bound Evans blue (EB) dye ${ }^{8}$ and ibuprofen, an NSAID decreased tumor growth in this model. ${ }^{9}$

Inflammatory processes may play a role in the development of tumor-associated edema. ${ }^{2.10} \mathrm{~A}$ number of mechanisms associated with inflammation alter microvessel permeability. Inflammatory cells such as polymorphonuclear leukocytes, macrophages and monocytes are known to release oxygen derived free radicals which may alter vessel permeability.11.12.13 Eicosanoids also are released by these cells and these compounds may play a role in altering microvascular permeability ${ }^{14}$ and in tumor growth. ${ }^{15}$ Scavengers of free radical species alter the effectiveness of the tumor promoter, phorbol myristate acetatel5 suggesting that tumor growth may be modulated by free radical scavengers.

From the Brain Research Laboratories, Experimental Research Unit, Department of Clinical Neurological Sciences, University of Western Ontario, Victoria Hospital, London, Ontario

Received May 3, 1990. Accepted in final form August 23, 1990

Reprint requests to: Dr. R.F. Del Maestro, Brain Research Laboratories, Victoria Hospital, 375 South Street, London. Ontario,

Canada N6A 4G5 
Studies have demonstrated that a group of novel 21-amino steroids, "lazaroids", are potent inhibitors of iron-dependent free radical mediated lipid peroxidation. ${ }^{16}$ One of these compounds, U74006F, modulates ischemic, ${ }^{17,18}$ traumatic ${ }^{19,20}$ and subarachnoid hemorrhage induced blood-brain barrier damage 21 in the central nervous system. This compound was not found to significantly decrease tumor growth or permeability in the C6 astrocytoma spheroid implantation model. 22

A second generation of these compounds have been developed. ${ }^{23}$ One of these compounds, U78517F, is a 2-methyl amino chroman and is a more effective inhibitor of in vitro iron-catalyzed lipid peroxidation than either U74006F or $\alpha$-alpha tocopherol. ${ }^{23}$ This compound is also effective in some of the traumatic and ischemic model systems used to assess U74006F. ${ }^{23}$

The purpose of these experiments was to examine the influence of U78517F on C6 astrocytoma growth in vitro and tumor growth and protein extravasation in the $\mathrm{C} 6$ astrocytoma spheroid implantation glioma model.

\section{Methods}

\section{In Vitro Studies}

The effect of U78517F on C6 astrocytoma cells during the exponential growth phase in culture was assessed by examining the growth characteristics, plating efficiency and the morphological appearance of cells. Astrocytoma cells were grown to subconfluency in minimum essential medium (MEM) supplemented with $15 \%$ fetal bovine serum (FBS), penicillin and streptomycin. All tissue culture supplies were obtained from Grand Island Biological Company, Mississauga, Canada. Nuncolon tissue culture dishes $(60 \mathrm{~mm})$ were inoculated with approximately 25-30,000 cells/dish. The cells were incubated at $37^{\circ} \mathrm{C}$ in a humidified incubator $\left(97 \%\right.$ air, $\left.3 \% \mathrm{CO}_{2}\right)$ for $1-2$ hours to achieve cell attachment. The medium was then removed and replaced with fresh medium containing 0 (control), 1.0, 5.0, $10.0,15.0$ or $20.0 \mu \mathrm{M}$ concentrations of the drug. The dishes were then returned to the incubator and cultured for varying time periods. The cells were examined at $24,48,72$ or 96 hours after the addition of the drug. For each time period, 2 dishes from each drug treatment concentration plus a control dish were removed and used for assessment.

The cells from one of the dishes from the different concentrations used were removed by trypsinization, diluted and counted to determine cell number as previously described. 24,25 Cells from the second culture dish from each group were trypsinized, diluted and a known number of these cells were seeded into fresh culture dishes and re-incubated. Within ten days, colony formation occurred and these were stained and counted to determine the plating efficiency (PE) of cells after treatment with different concentrations of the drug. 24,25

The above treatment protocol for the cultured C6 astrocytoma cells were repeated three times and, throughout the duration of the experiments, the cells were examined by light microscopy to determine whether drug treatment altered the morphology of the astrocytoma cells.

\section{In Vivo Studies}

To determine the effect of U78517F on C6 astrocytoma cells grown in vivo, the C6 astrocytoma spheroid implantation model in rats was used.
Tumor Production - Male Sprague-Dawley rats were implanted with $\mathrm{C} 6$ astrocytoma spheroids grown in spinner flask culture. This model of tumor production has been well-characterized and is described in detail elsewhere. 6 Briefly, spheroids measuring 300-400 $\mu \mathrm{M}$ in diameter were individually implanted into a suction defect in the parieto-occipital cerebral cortex of rats accessed through a burr hole craniectomy. Following the implantation procedure, the craniectomy was sealed with bone wax and the overlying skin was sutured. The animals were allowed to survive for 13 days after the day of implantation during which time they were treated with one of the treatment protocols. Rats were allowed free access to food and water for the duration of the experiment and were weighed before and during the experiment to monitor their general health.

Experimental Design - Rats were randomly allotted to one of the following drug treatment groups: high dose - long term (HDLT), low dose - long term (LDLT), high dose - short term (HDST) and saline injected controls which received an injection of saline equivalent in volume to the volume of solution used for the high dose treated rats. All injections were given intraperitoneally every 12 hours during the specified treatment period. High dose treated rats received $6 \mathrm{mg} / \mathrm{kg}$ of U78517F (mixed $10 \mathrm{mg} / \mathrm{ml}$ in saline) every 12 hours, while low dose treated rats received $2 \mathrm{mg} / \mathrm{kg}$. Both long term drug treatment groups (HDLT, LDLT) began treatment just before spheroid implantation. Drug treatment of either dose continued throughout the 13 day period allowed for tumor growth. The short term treatment group (HDST) initially received the drug on day 6 post-implantation, continuing to day 13 of the experiment. On day 13 , rats were sacrificed and tumor growth and tissue uptake of tracer were assessed in animals in each of the four groups.

Tumor Growth and Tracer Uptake - Rats were anesthetized with $100 \mathrm{mg} / \mathrm{ml}$ of ketamine hydrochloride (Rogarsetic, Rogar/STB Inc., Montreal, Canada) plus $0.5 \mathrm{ml}$ of Rompun (Haver/Chemargro Ltd., Etobicoke, Canada) and given an intravenous injection of $2 \mathrm{mg} / \mathrm{kg}$ of $2 \%$ Evans blue mixed in saline. The tracer was allowed to circulate for 1 hour before rats were perfused transcardially with $100 \mathrm{ml}$ of saline to clear the vasculature of any tracer remaining within the blood. The animals were then decapitated and their brains removed. Tumors were dissected free of the cortical tumor bed, weighed and divided in half and used to measure tumor wet and dry weights and tissue uptake of Evans blue into the tissue. Samples of peritumoral and contralateral cortex were also taken for measurement of Evans blue uptake.

Measurement Techniques - To determine dry weights of the samples, a weighed portion of the tissues were placed in a vacuum oven at $45^{\circ} \mathrm{C}$ for 4 days and then reweighed. Whole dry weights were calculated from the ratio of dry weight to wet weight of each sample. For measurement of Evans blue uptake, samples were placed into $1 \mathrm{ml}$ of formamide and extracted for three days. The amount of Evans blue in the extract was quantitated by spectrophotometry at $620 \mathrm{~nm}$ using formamide as a reference. ${ }^{6}$

Histology - A number of rats sacrificed on day 13 were used for histopathological studies. These animals were decapitated and the brains containing tumors were immersion fixed in $5 \%$ formalin. Tissue samples were dehydrated through a graded series of ethanols and xylene and then embedded in paraffin. The blocks were sectioned on a microtome, stained with hematoxylin and eosin and examined under the light microscope. 
Statistical Analysis - All results are reported as means \pm standard error of the mean. For each of the parameters measured in both the in vitro and in vivo studies, a one-way analysis of variance was used to determine whether there were any significant differences among the means. When a significant difference was observed, Dunnet's t-testing was performed to compare the respective control groups to the experimental groups to determine where the differences lay. For all statistical tests, the significance level was set at $\mathrm{p}<0.05$.

\section{Results}

\section{Effect of U78517F on C6 Cells in Vitro}

The growth rates of $\mathrm{C} 6$ astrocytoma cells in culture after treatment with varying concentrations of drug are shown in Figure 1. Over a 96-hour period, the growth in control cultures of astrocytoma cells occurred at an exponential rate. Addition of $1.0 \mu \mathrm{M}$ of the drug did not significantly affect growth rate; however, after 72 and 96 hours, the growth after treatment with this dose of the drug was reduced compared to the controls. The growth rate of cells was significantly inhibited when cultures were treated with 5.0,10.0,15.0 and $20.0 \mu \mathrm{M}$. At the highest drug concentration $(20.0 \mu \mathrm{M})$, there was a reduction in cell number after 48 hours with very few cells surviving beyond this time period.

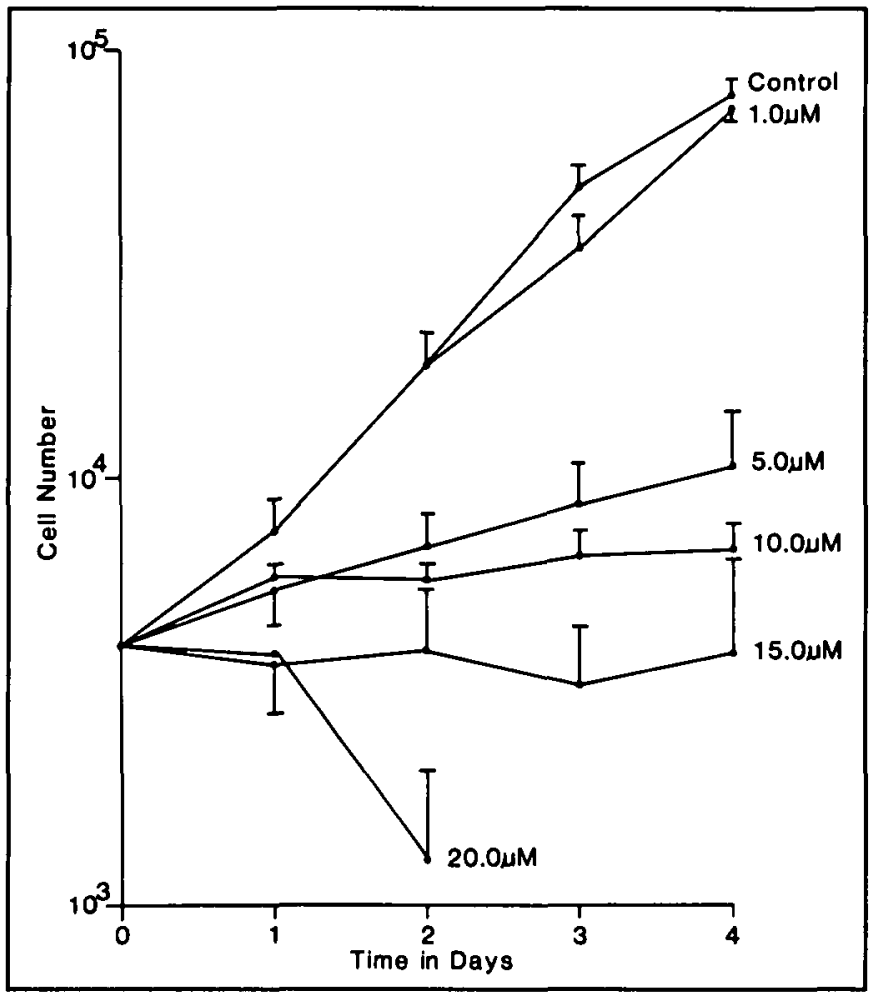

Figure I - Effect of U785I7F on C6 astrocytoma cells in vitro. Values represent means \pm SEM for three separate experiments. Addition of I.O $\mu M$ of the drug did not significantly affect growth rate when compared to controls. The growth rate of cells was significantly inhibited $(p<0.05)$ at all time points studied when cultures were treated with $5,10,15$ and $20 \mu M$ concentrations of $U 785 / 7 F$. At $20 \mu M$ concentration, very few cells survived beyond 48 hours.
Plating efficiency (\%) in control cultures of $\mathrm{C} 6$ astrocytoma cells in culture was $66.7 \pm 3.3 \%$. A slight decrease was observed after treatment with $1.0 \mu \mathrm{M}$ at the time periods studied, but this was not statistically significant (Figure 2). Treatment with $5.0 \mu \mathrm{M}$ of the drug caused a significant reduction in plating efficiency after 48 hours and this reduction was greater as the incubation period increased. After 96 hours, the plating efficiency was reduced to approximately $13 \%$. Almost no cells were able to plate out after treatment with $10.0,15.0$ or $20.0 \mu \mathrm{M}$ concentrations of the drug.

Morphologically, the cells retained a normal appearance for all treatment groups for at least up to the first 24 hours after treatment. After this time, cells incubated with the high drug concentrations were observed to lift off the surface of the culture plate and round up in appearance. These results indicate that treatment with $5.0 \mu \mathrm{M}$ and greater concentrations of U78517F dramatically inhibits the growth of $\mathrm{C} 6$ astrocytoma cells in culture.

\section{The Effect of U78517F on Tumors in Vivo}

\section{Pathology}

Of the 54 rats used for the study, 44 are included in the statistical analysis. The remaining rats were used for pathological assessment or did not have visually discernable tumors. Gross examination of the tumors at the time of removal demonstrated that they were uniformly spheroidal in shape and were stained with EB. The peritumoral area was only minimally stained with tracer. Histologically, there was a distinct border between the tumor and the surrounding cortical tissue as has been described previously. ${ }^{6}$ The tumors from the control and experimental groups were similar being composed of densely packed tumor cells. Mitotic figures were frequent, but endothelial proliferation was not prominent.

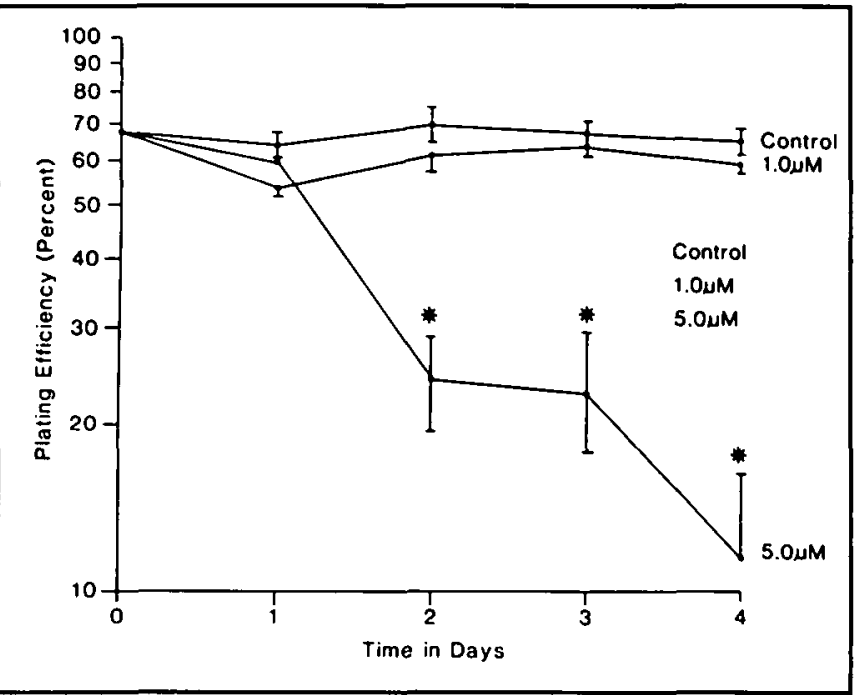

Figure 2 - Effects of U78517F on C6 astrocytoma plating efficiency. Values represent means $\pm S E M$ for three separate experiments and initial plating efficiency was calculated before any drug addition $(66.7 \pm 3.3 \%)$. Treatment with I $\mu M U 785 I 7 F$ did not significantly effect plating efficiency. Treatment with $5.0 \mu \mathrm{M}$ concentration significantly reduced plating efficiency $\left({ }^{*}\right.$ signifies $\left.p<0.05\right)$. Almost no cells plated after treatments with 10,15 and $20 \mu M U 78517 F$. 


\section{Experimental Results}

All three groups of rats receiving drug treatment had significantly smaller weight gain compared to rats in the control group (Figure 3).

Tumor wet and dry weights are shown in Figure 4. Control wet weight was $48.8 \pm 15.1 \mathrm{mg}$, HDLT group wet weight was $27.0 \pm 7.3 \mathrm{mg}$, LDLT group wet weight was $24.0 \pm 5.2 \mathrm{mg}$ and HDST group wet weight was $30.1 \pm 15.0 \mathrm{mg}$. Treatment with drug was associated with small tumors; however, this was not statistically significant. Tumor dry weights were $13.0 \pm 6.4 \mathrm{mg}$, $5.0 \pm 1.0 \mathrm{mg}, 5.4 \pm 1.0 \mathrm{mg}$ and $5.9 \pm 1.9 \mathrm{mg}$ for the control, HDLT, LDLT and HDST groups, respectively. The same overall pattern of non-significant decreased tumor size in the treated groups was seen. Drug treatment did not significantly influence contralateral cortex wet or dry weights (data not shown).

The amount of EB extravasated into the tumor (Figure 5) and peritumoral region (Figure 6), and contralateral cortex (data not shown) was not significantly different between control and experimental groups.

\section{Discussion}

Treatment of C6 astrocytoma cells growing in monolayer culture with $1 \mu \mathrm{M}$ U78517F results in a decrease in cell growth, but no significant changes in plating efficiency. These results suggest that $\mathrm{U} 78517 \mathrm{~F}$ at this concentration may inhibit cell division, but is not tumoricidal to C6 astrocytoma cells growing in monolayer culture. When U78517F is used at concentrations of $5 \mu \mathrm{M}$, both growth and plating efficiency decrease markedly after 24 hours. The use of 10,15 and $20 \mu \mathrm{M}$ concentrations is associated with marked alterations in $\mathrm{C} 6$ astrocytoma cell viability. Morphologically, the cells appeared relatively normal for 24 hours and then detached from the culture plate. The use of high concentrations of U74006F, another inhibitor of lipid peroxidation, is associated with the intracellular appearance of lipid like structures (unpublished results), but this was not seen using U78517F. The mechanisms of toxicity of U78517F are unclear, but appear to deserve further study.

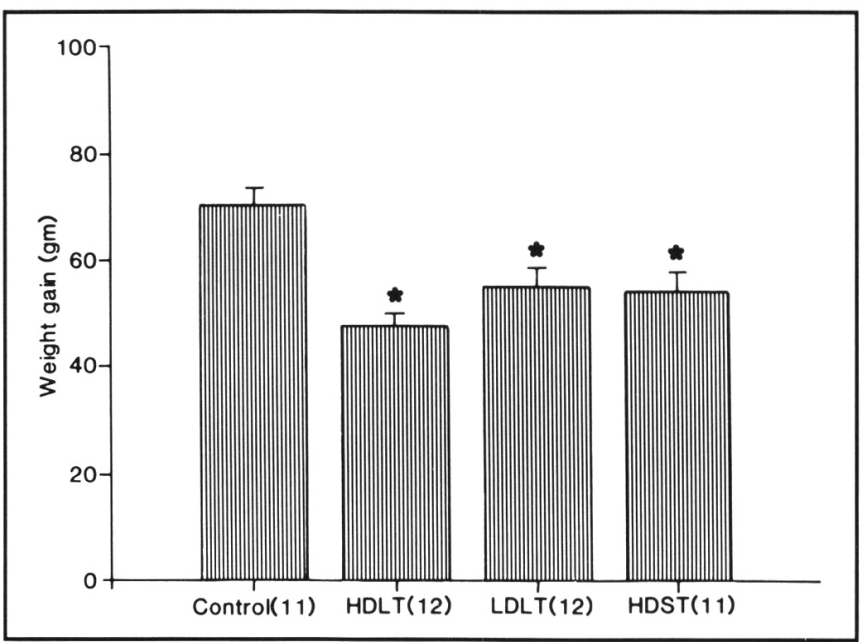

Figure 3 - Mean values $\pm S E M$ of body weight gain in control and treated groups. Numbers in parenthesis indicate the number of animals in each group and $(*)$ is used to indicate significant differ. ences from controls $(p<0.05)$.
The wet and dry weights of in vivo tumors were consistently smaller in all treatment groups when compared to the control group. The decreased size seen did not reach statistical significance in any drug treatment group assessed. All three regimes of drug treatment resulted in a significant decrease in expected animal weight gain. The cause of this decreased weight gain is unclear and was not seen when U74006F was used 22 in a similar dosing regime suggesting that the two compounds may have different systemic effects. The handling and intraperitoneal injections cannot account for the decreased weight gain seen since the controls were treated in a similar manner. Although the role that animal nutrition plays in the growth of C6 astrocytoma is not known, it could be speculated that some of the nonsignificant variability of tumor size seen in this study could be related to poor animal nutrition in the treatment groups. The concentration

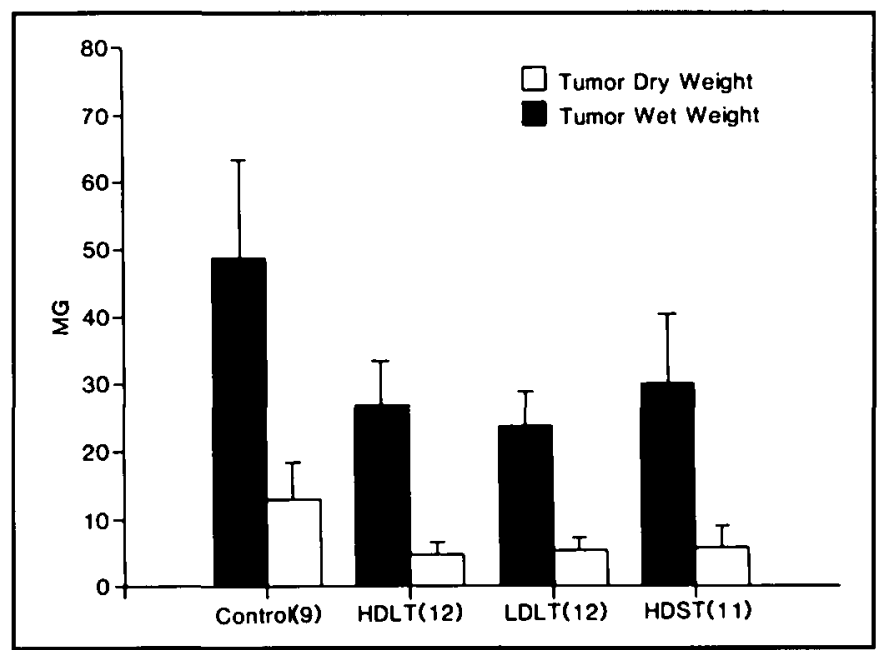

Figure 4 - Mean values \pm SEM of tumor wet and dry weights in control and treated groups. Number in parenthesis indicate the number of animals in each group. Treatment with $U 785 / 7 F$ did not significantly decrease tumor wet or dry weights when compared to controls.

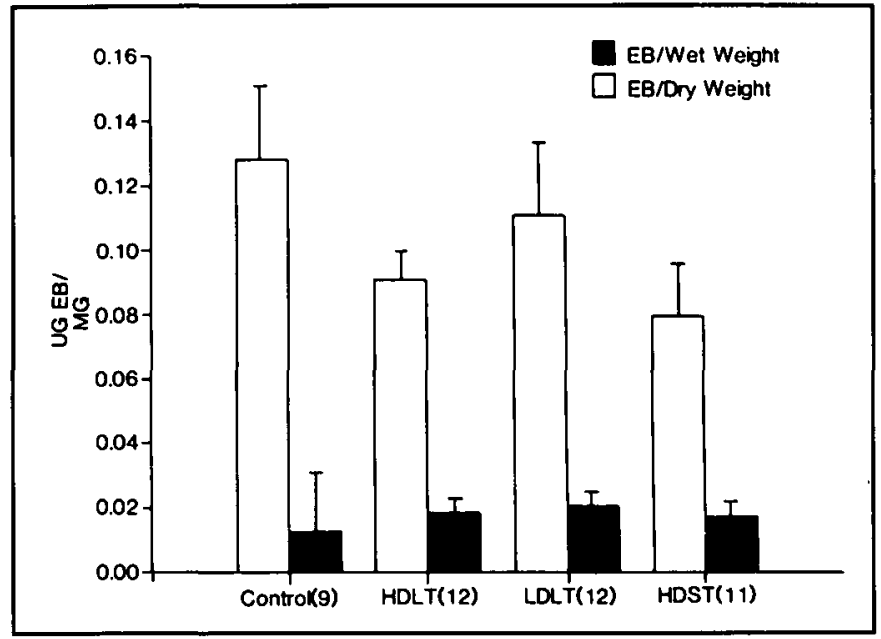

Figure 5 - Mean values \pm SEM of EB dye per mg wet tumor tissue and $E B$ dye per mig dry weight tissue in control and treated groups. Number in parenthesis indicates the number of animals in each group. Treatment with U78517F did not significantly decrease EB dye/mg of tumor tissue when compared to controls. 


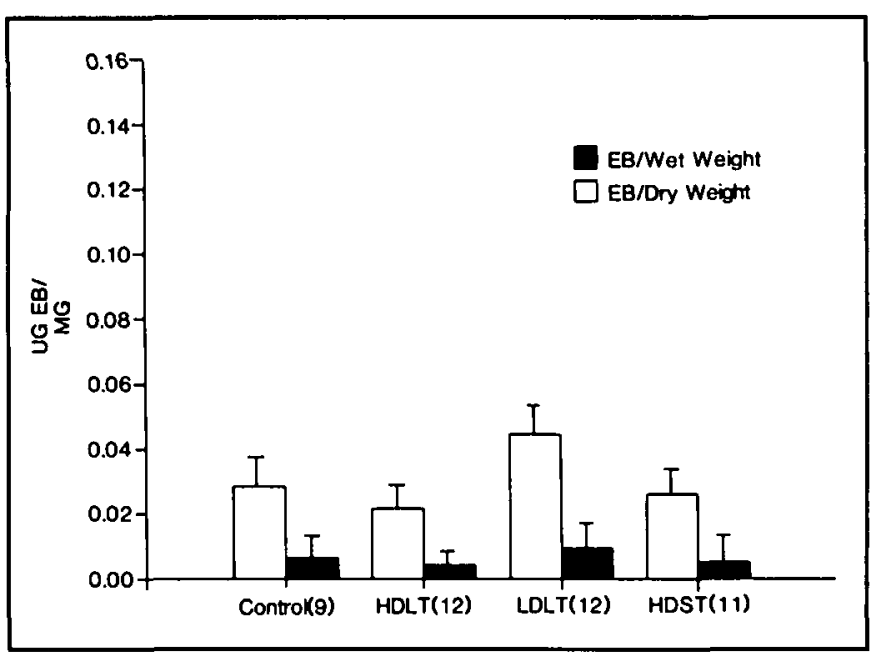

Figure 6-Mean values $\pm S E M$ of $E B$ dye per $m g$ wet peritumoral tissue and $E B$ dye per $m g$ dry peritumoral tissue in control and treated groups. Number in parenthesis indicates the number of animals in each group. Treatment with U785I7F did not significantly decrease $E B$ dye/mg of peritumoral tissue when compared to controls.

of $\mathrm{U} 78517 \mathrm{~F}$ that the $\mathrm{C} 6$ astrocytoma cells, contained in the implanted spheroid, were exposed to is unknown. However, this concentration may not have been high enough to exert a significant tumoricidal effect in the in vivo microenvironment.

The data reported in this communication demonstrate that treatment with U78517F at the concentrations tested does not significantly decrease protein flux into tumor or peritumoral tissue as measured by EB extravasation in rats implanted with C6 astrocytoma spheroids.

A number of mechanisms may be functional during the development and growth of a specific cerebral tumor which contribute to the types and amount of endothelial cell dysfunction seen and the resultant tumor-associated edema. ${ }^{2}$ The results of this study using U78517F and the results of a previous study using $\mathrm{U} 74006 \mathrm{~F}, 22$ both potent inhibitors of lipid peroxidation in vitro, suggest that lipid peroxidation may not play a predominate role in the endothelial alterations associated with cerebral tumors and expressed as tumor-associated edema. These compounds do appear to be effective in modulating tissue injury associated with experimental models of cerebral infarction and cerebral trauma. Our results would support the concept that although a number of disease processes may be associated with endothelial abnormalities, tumor-associated edema may be somewhat distinct in its response to steroids and its nonresponse to inhibitors of lipid peroxidation. The possibility that these compounds at high concentrations may have a role in decreasing cerebral glial tumor growth appears to warrant investigation.

\section{ACKNOWLEDGEMENTS}

The authors wish to thank Jo-Ann Dunn for her secretarial assistance. This work was supported by the Upjohn Company and the Brain Research Fund Foundation. Dr. Del Maestro is a recipient of an Ontario Ministry of Health Career Scientist Award.

\section{REFERENCES}

I. Barkowsky HM. Peritumoral edema. Prog Exp Tumor Res 1984; 27: $179-190$.
2. Del Maestro RF, Megyesi JF, Farrell Cl. Mechanisms of tumorassociated edema: A review. Can J Neurol Sci 1990; 17: 177-183.

3. Stewart PA, Hayakawa K, Farrell CL, et al. Quantitative study of microvessel ultrastructure in human peritumoral brain tissue. Evidence for blood-brain barrier defect. J Neurosurg 1987; 67: 697-705.

4. Coomber B, Stewart PA, Hayakawa F, et al. Quantitative morphology of glioblastoma multiforme microvessels. Structural basis of blood-brain barrier defect. J Neuro-Oncol 1987; 5: 299-307.

5. Auer R, Del Maestro RF, Andersen R. A simple and reproducible experimental in vivo glioma model. Can J Neurol Sci 1981; 8: 325-331.

6. Farrell CL, Stewart PA, Del Maestro RF. A new glioma model in rat: The $\mathrm{C} 6$ astrocytoma implantation technique permeability and vascular characterization. J Neuro-Oncol 1987; 4: 403-415.

7. Stewart PA, Hayakawa K, Hayakawa E, et al. A quantitative study of blood-brain barrier permeability ultrastructure in a new glioma model. Acta Neuropathol (Berl) 1985; 67: 96-102.

8. Reichman HR, Farrell CL, Del Maestro RF. Effects of steroids and nonsteroidal anti-inflammatory agents on vascular permeability in a rat glioma model. J Neurosurg 1986; 65: 233-237.

9. Farrell CL, Megyesi JF, Del Maestro RF. Effect of ibuprofen on tumor growth in the $\mathrm{C} 6$ spheroid implantation glioma model. J Neurosurg 1988; 68: 925-930.

10. Shinonaga $M$, Chang CC, Suzuki $N$, et al. Immunohistological evaluation of macrophage infiltrates in brain tumors. Correlation with peritumoral edema. J Neurosurg 1988; 68: 259-265.

11. Del Maestro RF, Thaw HH, Bjork J, et al. Free radicals as mediators of tissue injury. Acta Physiol Scand Suppl 1980; 492: 43-57.

12. Del Maestro RF. Free radicals as mediators of tissue injury. $I n$ : Dreosti l, ed. Trace Elements, Micronutrients and Free Radicals (In Press).

13. Del Maestro RF. Role of superoxide anion radicals in microvascular permeability and leukocyte behaviour. Can J Physiol Pharmacol 1982; 60: 1406-1414.

14. Del Maestro RF. An approach to free radicals in medicine and biology. Acta Physiol Scand Suppl 1980; 492: 153-168.

15. Johnson KJ, Ward PA. Inflammation and active oxygen species. In: Oberley LW, ed. Superoxide Dismutase Vol. 3. Boca Raton: CRC Press 1985; 129-142.

16. Braughler JM, Pregenzer JF, Chase RL, et al. Novel 21 -amino steroids as potent inhibitors of iron-dependent lipid peroxidation. J Biol Chem 1987; 262: 10438-10440.

17. Hall ED, Pazara KE, Braughler JM. 21 -amino steroid lipid peroxidation inhibitor $\mathrm{U} 74006 \mathrm{~F}$ protects against cerebral ischemia in gerbils. Stroke 1988; 19:997-1002.

18. Hall ED, Yonkers PA. Attenuation of post-ischemic cerebral hypoperfusion by the 21 -amino steroid U74006F. Stroke 1988 ; 19: 340-344.

19. Hall ED, Yonkers PA, McCall JM, et al. Effects of the 21-imino steroid U74006F on experimental head injury in mice. J Neurosurg 1988; $68: 456-461$.

20. Hall ED. Effects on the 21 -amino steroid U74006F on posttraumatic spinal cord ischemia. J Neurosurg 1988; 68; 462-465.

21. Zuccarello M, Anderson DK. Protective effect of a 21 -amino steroid on the blood-brain barrier following subarachnoid hemorrhage in rats. Stroke 1989; 20: 367-371.

22. Megyesi JF, Farrell CL, Del Maestro RF. Investigation of an inhibitor of lipid peroxidation U74006F on tumor growth and protein extravasation in the $\mathrm{C} 6$ astrocytoma spheroid implantation glioma model. J Neuro-Oncol 1990; 8: 133-137.

23. Hall ED, Braughler JM, Yonkers PA, et al. U78517F, a second generation lazaroid with potent antioxidant and cerebroprotective activity in models of CNS injury and ischemia. J Neurotrauma 1989; 6: 213-214.

24. Lordo CD, Stroude EC, Del Maestro RF. The effects of diphenylhydantoin on murine astrocytoma radiosensitivity. J Neuro-Oncol 1987; 5: 339-350.

25. Lordo CD, Stroude ED, Del Maestro RF. The effects of dexamethasone on C6 astrocytoma radiosensitivity. J Neurosurg 1989; 70: 767-773. 